\title{
Contemporary diagnosis of lower urinary tract dysfunction.
}

\section{[version 1; peer review: 2 approved]}

\author{
Peter Rosier (iD)
}

Department of Urology, University Medical Center Utrecht, Utrecht, The Netherlands

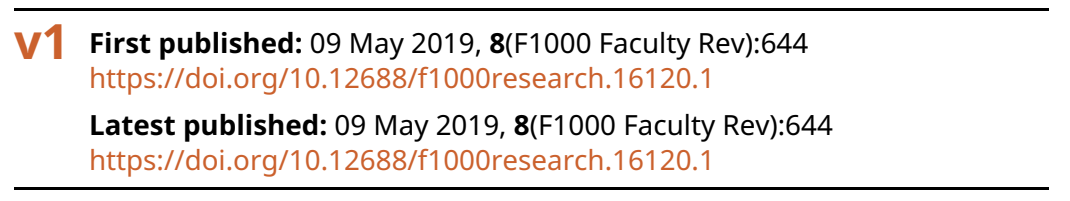

\section{Abstract}

Introduction: Diagnosis of lower urinary tract (LUT) dysfunction starts with categorization in clinical syndromes, and initial management is based on the assumptions about pathophysiology that these syndromes contain. However, clinical practice guidelines are ambiguous in clinical specialists' diagnosis of dysfunction after failure of initial management. This is a narrative and critical review of the existing evidence, and the aim is to suggest practice improvements in the process of clinical specialists' diagnosis for patients resistant to initial management.

Methods and Results: Evidence is collated on the basis of the author's personal preference in combination with good clinical practice general principles. Statements and suggestions to improve reflect personal opinion. For two groups of patients with LUT dysfunction, the strategy of initial diagnosis is summarized and desirable principles of secondary care diagnosis are discussed. More specifically, a structure for the contemporary care of women with signs and symptoms of urinary incontinence is described and for that of the group of men older than 45 years with symptoms of LUT dysfunction.

Conclusions: Urodynamic testing is the undisputed gold standard for objective assessment and is the only way to stage and grade the dysfunction. Clinical practice guidelines and clinical specialists are too modest about the use and applicability of objective or urodynamic testing for referred persons with LUT dysfunction that is resistant to initial pragmatic management. Objective assessment and diagnosis are mainstays in secondary care, and the indication to perform objective assessments in patients with LUT dysfunction should be advised much more specifically in guidelines and practice recommendations.

\section{Keywords}

Guidelines, diagnosis, urinary incontinence, lower urinary tract dysfunction, lower urinary tract symptoms, LUTS, OAB, BPH

\author{
Open Peer Review \\ Approval Status \\ 1 \\ 2 \\ version 1 \\ 09 May 2019 \\ Faculty Reviews are review articles written by the \\ prestigious Members of Faculty Opinions. The \\ articles are commissioned and peer reviewed \\ before publication to ensure that the final, \\ published version is comprehensive and \\ accessible. The reviewers who approved the final \\ version are listed with their names and \\ affiliations. \\ 1. Serdar Tekgul, Hacettepe University, Ankara, \\ Turkey \\ 2. Giuseppe Morgia, University of Catania, \\ Catania, Italy \\ Any comments on the article can be found at the \\ end of the article.
}


Corresponding author: Peter Rosier (p.f.w.m.rosier@umcutrecht.nl)

Author roles: Rosier P: Conceptualization, Formal Analysis, Investigation, Methodology, Writing - Original Draft Preparation, Writing Review \& Editing

Competing interests: No competing interests were disclosed.

Grant information: The author(s) declared that no grants were involved in supporting this work.

Copyright: @ 2019 Rosier P. This is an open access article distributed under the terms of the Creative Commons Attribution License, which permits unrestricted use, distribution, and reproduction in any medium, provided the original work is properly cited.

How to cite this article: Rosier P. Contemporary diagnosis of lower urinary tract dysfunction. [version 1; peer review: 2 approved] F1000Research 2019, 8(F1000 Faculty Rev):644 https://doi.org/10.12688/f1000research.16120.1

First published: 09 May 2019, 8(F1000 Faculty Rev):644 https://doi.org/10.12688/f1000research.16120.1 


\section{Introduction}

The normal lower urinary tract (LUT) stores urine and is able to evacuate this at suitable moments. It is likely that evolutionary advantage gave humankind this ability over continuously leaking urine or very frequent voiding. Leaving too many smell traces is not good in the wild. When born, and even earlier, a child has the abilities to store and void; however, the bladder itself dictates the frequency in early life. An autonomic (pontine-sacral) reflex is built in to ensure this ${ }^{1}$. This autonomic reflex becomes controllable during potty training and social continence is the endpoint. Anatomy, physiology, or function (or a combination of these) may be or become abnormal and result in signs and symptoms of dysfunction. Dysfunction of the LUT has many faces and I discuss two important types in this article with the aim to give arguments to raise the standard of care with regard to diagnosis in secondary-referred-care. These two groups are very prevalent and the recommendations in the guidelines for secondary care management are especially ambiguous about the relevance of adequate objective diagnosis for these: adult women with symptoms of urinary incontinence (UI) or too frequent voiding (or both) and adult men older than 45 years of age with symptoms of LUT dysfunction. I present a narrative, personal, and critical review of the evidence and of general contemporary good medical principles regarding the diagnostic process for patients with LUT dysfunction and the ultimate aims are to improve care and outcome and to reduce (potential) harm for these patients.

Persons with LUT dysfunction may seek care for their symptoms. Undoubtedly, there is an individual threshold for the decision to seek professional care ${ }^{2}$ and without a doubt this threshold has wide intra-individual variation. Any person with symptoms who arrives at professional care enters a form of diagnostic process. Diagnosis of LUT dysfunction would first of all try to separate whether the dysfunction is secondary: related to the person's medication (given for other diseases), to other diseases (for example, neurological, urinary tract inflammation or neoplasm), or to other dysfunction (for example, immobility or mental incapability to go to the toilet). Subsequently, the signs and symptoms that the patients report are categorized, so that a useable differential diagnosis can be obtained. I discuss women with symptoms and afterward the men with symptoms of LUT dysfunction.

\section{Women with symptoms of urinary incontinence}

The initial workup of a woman who presents with UI includes history and clinical exam to be completed with a drinking voiding diary, reporting at least 24 hours, as is recommended in every practice guideline. The information gathered is useful to get a first impression of the likelihood of the dysfunction that is responsible for the symptoms ${ }^{3}$. UI by itself is not life-threatening and when this sign of dysfunction is (with reasonable certainty) not the result of other diseases, it is possible to start an initial management, usually directed either to the pelvic floor-striated-muscles or to the bladder muscle (m. detrusor) $)^{4}$.

Initial conservative management is usually life style or fluid intake management (or both) with the help of the voiding diary.
Further conservative management is based on, for example, pelvic floor muscle training or medication (or both) to alleviate detrusor overactivity. When the patient reports that this is not successful, a referral to clinical specialist care may follow sooner or later in a proportion of patients. Transition from primary care to secondary care means, in common good medical practice, that objective confirmation of disease or dysfunction is sought, potentially (but not rarely) leading to a revision of the earlier diagnosis, which has been based on clinical signs and symptoms only.

However, the contemporary guidelines meant to support medical specialist care are surprisingly ambiguous regarding specific diagnosis of dysfunction for women with UI or too frequent micturitions or both ${ }^{5-7}$. Laboratory tests, imaging, and function testing are mainstays of the diagnostic process in medical specialist care in hospitals where radiologists, clinical chemists, bacteriologists, and so on are renowned specialists. Laboratory tests are relevant for women with UI to exclude hematuria or renal dysfunction (or both), and sometimes imaging of the kidneys is relevant. UI may be the result of detrusor muscle overactivity (detrusor overactivity incontinence) or of weakness of the bladder outlet closure mechanism (stress UI) or both. However, imaging of the LUT or the pelvic muscle closure mechanism (or both) with lateral cystography ${ }^{8}$, which is abandoned nowadays, but also with magnetic resonance imaging ${ }^{9}$ or perineal ultrasound ${ }^{10}$ has never given results that were specific or sensitive enough to predict the type of UI dysfunction. Yes, the studies referred to here have been able to show elements of pathophysiology of-especially-stress UI; however, none of these has shown any relevance for the exclusion of the detrusor (overactivity) causing the UI. And none of these has been shown to be helpful in the exclusion of abnormalities of bladder-filling sensation or of voiding problems. Furthermore, not much progress has been made in subtyping or staging and grading of the continence dysfunction on the basis of imaging.

Staging and grading of the dysfunction are relevant for the selection of treatment in almost every area in health care or disease. Little is known about the staging or grading of UI. The amount of urinary leakage can be assessed in a standardized way ${ }^{11}$ but this is to be regarded as a clinical staging. Apart from the fact that the amount of urinary leakage, as measured with a standard pad weighing test, associates only weakly with bother ${ }^{12}$, this test is imperfect in the assessment of the type of dysfunction, as dichotomized above ${ }^{13}$. Bother is another element of clinical staging. However, some women may have, for example, a very little amount of urine loss and experience a high degree of bother. Every clinician is well aware of the lack of association of expressed symptoms and existing pathology and knows that very serious (for example, malignant) disease can exist without any symptoms and vice versa.

It is difficult to define, on the basis of clinical staging, whether incontinence is severe or not severe. Objective criteria to separate severe from not severe UI do not exist at present. If severe would be translated as being more difficult to treat or as requiring a specific treatment, very low leak-point pressure (or intrinsic sphincter deficiency) would potentially lead to a specific management ${ }^{14-16}$. However, it is never scientifically 
demonstrated that, for example, larger-volume UI is more difficult to treat than small-volume low-frequency urine loss.

Urodynamic testing results in objective information about the function of the LUT. Not only continence function but also detrusor volume adaptation (compliance), bladder-filling sensation, and leak-point pressures can be determined during the filling phase. Furthermore, detrusor contraction strength and bladder outflow resistance during voiding become quantifiable ${ }^{17}$.

Very low leak-point pressure would, as mentioned above, be a relevant and specific outcome of urodynamic testing. However, UI is not always observable or provocable during urodynamic testing but I do not regard this as a problem. UI is a symptom that is hardly ever presented as a false positive and it is reproducible without any equipment. The most important goal of urodynamic testing in patients with clinical stress UI (syndrome) is to try to exclude all LUT dysfunctions, except stress $\mathrm{UI}^{18}$. On the other hand, the practice of provocation of (stress) UI during a clinical exam has been described in very many ways. During urodynamics, stress provocation is not better standardized. Only recently has there been an initiative to "uniformize" the clinical cough stress test $\mathrm{t}^{19}$.

Urodynamic diagnoses as detrusor overactivity, lack of filling compliance, lack of sensation, or ineffective voiding, would lead to the diagnosis of "not typical" stress UI and would have relevance when the patient has, for example, too frequent micturitions as (one of the) symptom(s) ${ }^{18}$. Not typical stress UI should be treated specifically, directed to the predominant pathophysiology and individually based, on objective assessment.

Direct measurements of bladder outlet pressure (urethral pressure) in diverse ways (for example, profile) have demonstrated plausible results; the lower the "sphincter" pressure, the lesser the likelihood of continence. However, the diagnostic specificity is, like imaging, too low to discriminate between two types of UI and the remainder of the LUT function remains obscure. Patients with urodynamically confirmed genuine stress UI have been considered the ideal or only candidates for surgery since a 1980 publication by Cardozo and Stanton $^{18}$, especially in an era when surgery was invasive and required lower abdominal incision. The new century began, 20 years later, with the introduction of the tension-free-mid-urethral-vaginal tape for the treatment of "genuine stress urinary incontinence" ${ }^{20}$. This treatment was introduced as a day-case procedure with local anesthesia, and outcomes were similar to those of the gold standard -Burch operation. This caused a revolution in the treatment of female stress UI but also lowered the threshold to surgically intervene. The diagnosis of genuine -or urodynamic stress UI, based on urodynamic exclusion of other or coexisting LUT dysfunctions, has gradually been slimmed down to "stress UI", leaving out "genuine" and becoming a - yet poorly defined-clinical syndrome on the basis of subjective signs and symptoms ${ }^{21}$. As a counterpart, the symptoms are frequently expressed with the existence of another common dysfunction, in combination with symptoms of UI; urodynamic detrusor overactivity were captured in a syndrome as well; the overactive bladder syndrome officially introduced as a syndrome $^{22}$, however alike "stress incontinence" applied in a simplified way by many, confusing "a syndrome" with "a disease". Although patients with detrusor overactivity frequently report symptoms of this syndrome, the syndrome is not at all specific for detrusor overactivity. Patients are-expectably-not able to precisely describe their dysfunction very well ${ }^{23}$ and their descriptions do not automatically fit the medical concepts. Consequently, a "mixed incontinence" category, based on reported symptoms, arrived without any pathophysiological foundation and no evidence of any specific management ${ }^{24}$.

Clinical syndromes are relevant, needed, and helpful to ease communication among professionals and are helpful to initiate conservative management. However, with regard to UI syndromes, there is a wealth of evidence to confirm that these are not specific and not sensitive enough to delineate the pathophysiology, especially not in the referred population ${ }^{25}$. Failure of initial conservative management in primary health care would first be considered a failure of diagnosis (as a result of ex-juvantibus management) and leads to reconsideration of the diagnosis or referral to secondary care (or both). In general, referral implies assessment of objective evidence for disease or dysfunction by making use of the abovementioned supporting specialists. This is hardly the case for patients with UI where syndromes have become the mainstay of diagnosis. Moreover, a good definition of failure of initial management is lacking ${ }^{26}$ and systematic follow-up diagnosis is deemed to require further phenotyping ${ }^{27}$. That a specific urodynamic diagnosis is helpful and needed in patients with failure after initial management is demonstrated in a prospectively randomized study in which $36 \%$ of the patients included were shown to have urodynamic results that (outside the construct of this trial) would not lead to the one of the interventions tested. More precisely, only $64 \%$ of the patients (231 out of 364) included with the overactive bladder syndrome showed detrusor overactivity on urodynamic testing and eventually would be potential candidates for botulin toxin injections or sacral neuromodulation. The patients without detrusor overactivity failed on initial management for the overactive bladder syndrome, and the urodynamic testing has demonstrated why. This is in agreement with all of the evidence that demonstrates that the syndromes are only weak indicators of pathophysiological diagnosis ${ }^{25}$.

Clinical staging on the basis of signs and symptoms is relevant on the one hand; on the other hand, staging and grading of pathophysiology are equally important in secondary care to be able to individualize management, to prevent unnecessary surgery and interventions, and to improve management outcomes for all patients after failed initial management. Objective assessment of (LUT) dysfunction (diagnosis) is not designed to "improve the outcome of surgery"; it is designed to allocate individuals to a management strategy with a demonstrated mechanism of action toward their dysfunction.

Contemporary diagnosis of UI in adult women is recommended to be based on signs and symptoms, reported or observed (or both $)^{5-7}$, but it seems worthwhile to better delineate the syndromes and better define failure of initial management ${ }^{21}$. 
Clinical specialist diagnosis of patients with failed initial treatment is endangered to fall prey to nihilism. Too many patients are advised a 'one size fits all' invasive management without objective and individualized staging and grading of the dysfunction. Staging and grading of dysfunction and disease are mainstays in secondary care, and the patients with failure after initial management for their UI deserve objective assessment because they worry about the origin of their symptoms $\mathrm{s}^{23}$ and expect information about cause and about the specific and individualized management of their dysfunction $^{28}$.

\section{Men with lower urinary tract dysfunction}

Elderly men with symptoms of LUT dysfunction have "prostatism". This simple concept was apparently valid until almost 1980. The prostate tends to continue growing after the fourth decade of a man's life and as a result of human anatomy the growing prostate may cause urinary tract symptoms ${ }^{29}$. That this epidemiological coincidence of later-life prostate growth and "prostatism" as the syndrome has led to unjustified causation and generalization was shown in a pivotal article ${ }^{30}$. Not all LUT symptoms are the result of bladder outflow obstruction (BOO) in every man. Not all men have BOO, and elderly men may have LUT symptoms without prostatic enlargement. Surgery for prostatism was gradually replaced with less invasive and medical management of LUT dysfunction. Urodynamic assessment (confirmation) with grading of $\mathrm{BOO}$ has been used to validate these new treatment options designed specifically to relieve $\mathrm{BOO}^{31-34}$. Apart from urodynamic outcomes, test-retest evaluations of urodynamic quantification of $\mathrm{BOO}$ have been published ${ }^{35,36}$. It was also confirmed that prostate size is associated with the likelihood of $\mathrm{BOO}^{37}$. Flow rate is reduced in many men with symptoms of LUT dysfunction, and the combination of prostate enlargement and reduced flow rate with or without post-void residual is a better predictor of $\mathrm{BOO}$ than reported symptoms alone $\mathrm{s}^{38-40}$. Grading of BOO with a pressure flow plot has become standard for elderly males. ${ }^{41}$, In a simplified form of pressure flow quantification, the International Continence Society (ICS) provisional bladder outlet index (BOOI or initially: A-G number), introduced herein can be used to numerically quantify the grade of BOO. Furthermore, as outlined above, grading of the effect of management directed to the outflow obstructive component of the dysfunction as well as (safety) monitoring of expectative management is possible. Pressure flow analysis is clearly relevant in the management of elderly male patients and would lead patients (and physicians) away from treatment on the basis of symptoms and bother ${ }^{42}$. Sometimes, reports give a wide variation in prostate sizes and flow rates that cannot very likely associate with $\mathrm{BOO}$ at the lower end of the prostate sizes and at the upper end of the flow rate ${ }^{43}$. In many published reports, urodynamics has not clearly been used to select men for invasive management or to exclude them if no BOO was diagnosed. This leaves the possibility that a patient was operated with a technique aiming at reduction of outflow resistance without relevant BOO present.

For referred elderly men with LUT dysfunction persisting with or after initial management, diagnosis should not only confirm or exclude BOO. Urodynamic testing also gives the possibility to quantify detrusor voiding contraction strength as well as detrusor volume adaptation and relaxation. Detrusor overactivity is very prevalent in elderly men and is undeniably intermingling in the male LUT dysfunction syndrome. Elderly men without (high-grade) BOO and with detrusor overactivity would profit from specific medical management. Men with high-grade BOO and detrusor overactivity may deserve a less expectative management than men with a moderate grade of BOO without detrusor overactivity. Regrettably, this stratification of disease, as was already introduced in $1979^{30}$, has been overwhelmed with the (enthusiastic) introduction of minimally invasive and medical management options for elderly men with symptoms but also for these options: "one size fits all" -management strategies do not exist in health care, especially not when initiated on the basis of symptoms only. Physiological demonstration of the mechanism of action and of effect size should be the basis of the introduction of every new management option (surgical, instrumental, or medical) for LUT dysfunction. Individualization of management on the basis of objectively assessed pathophysiology should be the gold standard in every clinical specialist's practice.

\section{Conclusions}

Contemporary diagnosis of LUT dysfunction, especially of UI or too frequent voiding in women over 40 years of age (or both), and of symptoms of dysfunction in men over 45 years of age begins with a LUT syndrome diagnosis on the basis of clinical epidemiology and reported symptoms and signs, including fluid balance. Initial non-invasive management can safely be based on this. However, I plead that, if initial management fails, both categories of patients deserve objective assessment of their LUT function as the basis for further specific and individualized management. Contemporary medical specialists' guidelines are far too modest about the indication and applicability of objective testing for persons with LUT dysfunction, and existing evidence should be included. Objective testing is inescapable and invaluable in secondary health care on the basis of good practice, and urodynamic testing is the undisputed gold standard for this objective assessment and the only way to stage and grade the dysfunction. Individualized management on the basis of objective diagnosis is the paradigm of modern health care. Functional urology should not lag behind.

\section{Grant information}

The author(s) declared that no grants were involved in supporting this work. 
1. Tadic SD, Holstege G, Griffiths DJ: The CNS and bladder dysfunction. F1000 Med Rep. 2012; 4: 20

PubMed Abstract | Publisher Full Text | Free Full Text

2. F Helfand BT, Smith AR, Lai HH, et al:: Prevalence and Characteristics of Urinary Incontinence in a Treatment Seeking Male Prospective Cohort: Results from the LURN Study. J Urol. 2018; 200(2): 397-404.

PubMed Abstract | Publisher Full Text | Free Full Text | F1000 Recommendation

3. Abrams P, Andersson KE, Apostolidis A, et al.: 6th International Consultation on Incontinence. Recommendations of the International Scientific Committee: EVALUATION AND TREATMENT OF URINARY INCONTINENCE, PELVIC ORGAN PROLAPSE AND FAECAL INCONTINENCE. Neurourol Urodyn. 2018; 37(7): 2271-2.

PubMed Abstract | Publisher Full Text

4. $\mathrm{F}$ Lukacz ES, Santiago-Lastra $\mathrm{Y}$, Albo ME, et al:: Urinary Incontinence in Women: A Review. JAMA. 2017; 318(16): 1592-604.

PubMed Abstract | Publisher Full Text | F1000 Recommendation

5. Abrams PCL, Cardozo L, Khoury AE, et al:: Incontinence: 5 th International Consultation on Incontinence. Paris, France; 2013.

Reference Source

6. F Kobashi KC, Albo ME, Dmochowski RR, et al:: Surgical Treatment of Female Stress Urinary Incontinence: AUA/SUFU Guideline. J Urol. 2017; 198(4): 875-83. PubMed Abstract | Publisher Full Text | F1000 Recommendation

7. Burkhard FC, Bosch JLHR, Cruz F, et al.: Urinary incontinence. Reference Source

8. Diokno AC, Dimaculangan RR, Lim EU, et al:: Office based criteria for predicting type II stress incontinence without further evaluation studies. J Urol. 1999; 161(4): 1263-7.

PubMed Abstract | Publisher Full Text

9. F Pontbriand-Drolet S, Tang A, Madill SJ, et al.: Differences in pelvic floor morphology between continent, stress urinary incontinent, and mixed urinary incontinent elderly women: An MRI study. Neurourol Urodyn. 2016; 35(4): 515-21.

PubMed Abstract | Publisher Full Text | F1000 Recommendation

10. Fritel X, Zabak K, Pigne A, et al:: Predictive value of urethral mobility before suburethral tape procedure for urinary stress incontinence in women. $J$ Urol. 2002; 168(6): 2472-5

PubMed Ab

11. Krhut J, Zachoval R, Smith PP, et al:: Pad weight testing in the evaluation of urinary incontinence. Neurourol Urodyn. 2014; 33(5): 507-10. PubMed Abstract | Publisher Full Text

12. Stach-Lempinen $B$, Kirkinen $P$, Laippala $P$, et al:: Do objective urodynamic or clinical findings determine impact of urinary incontinence or its treatment on quality of life?. Urology. 2004; 63(1): 67-71; discussion 71-2. PubMed Abstract | Publisher Full Text

13. Costantini E, Lazzeri M, Bini V, et al:: Sensitivity and specificity of one-hour pad test as a predictive value for female urinary incontinence. Urol Int. 2008; 81(2) 153-9.

PubMed Abstract | Publisher Full Text

14. Schierlitz L, Dwyer PL, Rosamilia A, et al:: Three-year follow-up of tension-free vaginal tape compared with transobturator tape in women with stress urinary incontinence and intrinsic sphincter deficiency. Obstet Gynecol. 2012; 119(2 Pt 1): 321-7.

PubMed Abstract

15. F Kim HG, Park HK, Paick SH, et al:: Comparison of Effectiveness between Tension-Free Vaginal Tape (TVT) and Trans-Obturator Tape (TOT) in Patients with Stress Urinary Incontinence and Intrinsic Sphincter Deficiency. PLOS One. 2016; 11(5): e0156306.

PubMed Abstract | Publisher Full Text | Free Full Text | F1000 Recommendation

16. Bayrak Ö, Osborn D, Reynolds WS, et al:: Pubovaginal sling materials and their outcomes. Turk J Urol. 2014; 40(4): 233-9.

PubMed Abstract | Publisher Full Text | Free Full Text

17. Rosier PFWM, Schaefer W, Lose G, et al.: International Continence Society Good Urodynamic Practices and Terms 2016: Urodynamics, uroflowmetry, cystometry, and pressure-flow study. Neurourol Urodyn. 2017; 36(5): 1243-60. PubMed Abstract | Publisher Full Text

18. Cardozo LD, Stanton SL: Genuine stress incontinence and detrusor instability-a review of 200 patients. Br J Obstet Gynaecol. 1980; 87(3): 184-90. PubMed Abstract | Publisher Full Text

19. Guralnick ML, Fritel X, Tarcan T, et al.: ICS Educational Module: Cough stres test in the evaluation of female urinary incontinence: Introducing the ICSUniform Cough Stress Test. Neurourol Urodyn. 2018; 37(5): 1849-55. PubMed Abstract | Publisher Full Text

20. Ulmsten $\mathrm{U}$, Falconer $\mathrm{C}$, Johnson $\mathrm{P}$, et al: : A multicenter study of tension-free vaginal tape (TVT) for surgical treatment of stress urinary incontinence. Int Urogynecol J Pelvic Floor Dysfunct. 1998; 9(4): 210-3. PubMed Abstract | Publisher Full Text

21. Rosier PF, Giarenis I, Valentini FA, et al.: Do patients with symptoms and signs of lower urinary tract dysfunction need a urodynamic diagnosis? ICI-RS 2013.
Neurourol Urodyn. 2014; 33(5): 581-6.

PubMed Abstract | Publisher Full Text

22. Abrams $\mathrm{P}$, Cardozo L, Fall M, et al:: The standardisation of terminology in lower urinary tract function: report from the standardisation sub-committee of the International Continence Society. Urology. 2003; 61(1): 37-49. PubMed Abstract | Publisher Full Text

23. Coyne KS, Sexton CC, Kopp Z, et al.: Assessing patients' descriptions of lowe urinary tract symptoms (LUTS) and perspectives on treatment outcomes: results of qualitative research. Int J Clin Pract. 2010; 64(9): 1260-78. PubMed Abstract | Publisher Full Text

24. F Myers DL: Female mixed urinary incontinence: a clinical review. JAMA. 2014; 311(19): 2007-14.

PubMed Abstract | Publisher Full Text | F1000 Recommendation

25. F Finazzi-Agro E, Gammie A, Kessler TM, et al.: Urodynamics Useless in Female Stress Urinary Incontinence? Time for Some Sense-A European Expert Consensus. Eur Urol Focus. 2018; pii: S2405-4569(18)30215-3.

PubMed Abstract | Publisher Full Text | F1000 Recommendation

26. F Phé V, de Wachter S, Rouprêt M, et al.: How to define a refractory idiopathic overactive bladder? Neurourol Urodyn. 2015; 34(1): 2-11.

PubMed Abstract | Publisher Full Text | F1000 Recommendation

27. F Apostolidis A, Averbeck MA, Sahai A, et al:: Can we create a valid treatment algorithm for patients with drug resistant overactive bladder (OAB) syndrome or detrusor overactivity (DO)? Results from a think tank (ICI-RS 2015)

Neurourol Urodyn. 2017; 36(4): 882-93.

PubMed Abstract | Publisher Full Text | F1000 Recommendation

28. Bowling A, Rowe G, Lambert N, et al:: The measurement of patients expectations for health care: A review and psychometric testing of a measure of patients' expectations. Health Technol Assess. 2012; 16(30): i-xii, 1-509. PubMed Abstract | Publisher Full Text

29. F Bosch JL, Bangma $\mathrm{CH}$, Groeneveld FP, et al:: The long-term relationship between a real change in prostate volume and a significant change in lower urinary tract symptom severity in population-based men: The Krimpen study. $J$ Urol. 2008; 53(4): 819-25; discussion 825-7.

PubMed Abstract | Publisher Full Text | F1000 Recommendation

30. Abrams PH, Farrar DJ, Turner-Warwick RT, et al.: The results of prostatectomy: A symptomatic and urodynamic analysis of 152 patients. J Urol. 1979; 121(5): 640-2.

PubMed Abstract | Publisher Full Text

31. Tammela TL, Schäfer W, Barrett DM, et al:: Repeated pressure-flow studies in the evaluation of bladder outlet obstruction due to benign prostatic enlargement. Finasteride Urodynamics Study Group. Neurourol Urodyn. 1999; 18(1): 17-24.

PubMed Abstract | Publisher Full Text

32. Te Slaa E, de Wildt MJ, Rosier PF, et al.: Urodynamic assessment in the laser treatment of benign prostatic enlargement. Br J Urol. 1995; 76(5): 604-10. PubMed Abstract | Publisher Full Text

33. Witjes WP, Robertson A, Rosier PF, et al:: Urodynamic and clinical effects of noninvasive and minimally invasive treatments in elderly men with lowe urinary tract symptoms stratified according to the grade of obstruction. Urology. 1997; 50(1): 55-61.

PubMed Abstract | Publisher Full Text

34. Witjes WP, Rosier PF, Caris CT, et al:: Urodynamic and clinical effects of terazosin therapy in symptomatic patients with and without bladder outlet obstruction: a stratified analysis. Urology. 1997; 49(2): 197-205; discussion 205-6.

PubMed Abstract | Publisher Full Text

35. Rosier PF, de la Rosette JJ, Koldewijn EL, et al.: Variability of pressure-flow analysis parameters in repeated cystometry in patients with benign prostatic hyperplasia. J Urol. 1995; 153(5): 1520-5.

PubMed Abstract | Publisher Full Text

36. Witjes WP, deWildt MJ, Rosier PF, et al:: Variability of clinical and pressureflow study variables after 6 months of watchful waiting in patients with lower urinary tract symptoms and benign prostatic enlargement. $J$ Urol. 1996; 156(3): 1026-34.

PubMed Abstract | Publisher Full Text

37. Rosier PF, de la Rosette JJ: Is there a correlation between prostate size and bladder-outlet obstruction? World J Urol. 1995; 13(1): 9-13.

PubMed Abstract | Publisher Full Text

38. Madersbacher S, Klingler HC, Djavan B, et al.: Is obstruction predictable by clinical evaluation in patients with lower urinary tract symptoms? $\mathrm{Br} J$ Urol. 1997; 80(1): 72-7.

PubMed Abstract | Publisher Full Text

39. Rosier PF, de Wildt MJ, Wijkstra $\mathrm{H}$, et al.: Clinical diagnosis of bladder outlet obstruction in patients with benign prostatic enlargement and lower urinary tract symptoms: development and urodynamic validation of a clinical prostate score for the objective diagnosis of bladder outlet obstruction. J Urol. 1996 155(5): 1649-54.

PubMed Abstract | Publisher Full Text 
40. F Kim M, Cheeti A, Yoo C, et al.: Non-invasive clinical parameters for the prediction of urodynamic bladder outlet obstruction: analysis using causal Bayesian networks. PLoS One. 2014; 9(11): e113131.

PubMed Abstract | Publisher Full Text | Free Full Text | F1000 Recommendation

41. Griffiths D, Höfner K, van Mastrigt R, et al.: Standardization of terminology of lower urinary tract function: pressure-flow studies of voiding, urethral resistance, and urethral obstruction. International Continence Society Subcommittee on Standardization of Terminology of Pressure-Flow Studies.
Neurourol Urodyn. 1997; 16(1): 1-18. PubMed Abstract | Publisher Full Text

42. Apostolidis A, de Nunzio C, Tubaro A: What determines whether a patient with LUTS seeks treatment? ICI-RS 2011. Neurourol Urodyn. 2012; 31(3): 365-9. PubMed Abstract | Publisher Full Text

43. Lee CJ, Cho MC, Ku JH, et al.: Changes in nocturia after photoselective vaporization of the prostate for patients with benign prostatic hyperplasia. Korean J Urol. 2010; 51(8): 531-6.

PubMed Abstract | Publisher Full Text | Free Full Text 


\section{Open Peer Review}

\section{Current Peer Review Status:}

\section{Editorial Note on the Review Process}

Faculty Reviews are review articles written by the prestigious Members of Faculty Opinions. The articles are commissioned and peer reviewed before publication to ensure that the final, published version is comprehensive and accessible. The reviewers who approved the final version are listed with their names and affiliations.

\section{The reviewers who approved this article are:}

\section{Version 1}

\section{Giuseppe Morgia}

Urology Section, Department of Surgery, University of Catania, Catania, Italy

Competing Interests: No competing interests were disclosed.

\section{Serdar Tekgul}

Division of Paediatric Urology, Department of Urology, Faculty of Medicine, Hacettepe University, Ankara, Turkey

Competing Interests: No competing interests were disclosed.

The benefits of publishing with F1000Research:

- Your article is published within days, with no editorial bias

- You can publish traditional articles, null/negative results, case reports, data notes and more

- The peer review process is transparent and collaborative

- Your article is indexed in PubMed after passing peer review

- Dedicated customer support at every stage

For pre-submission enquiries, contact research@f1000.com 